
NBSIR 83-2640

\section{SENSORS FOR EFFICIENT ENERGY UTILIZATION IN THE PAPER INDUSTRY}
J. R. Whetstone
E. G. Johnsen

U.S. DEPARTMENT OF COMMERCE

National Bureau of Standards

National Engineering Laboratory

Center for Chemical Engineering

Washington, DC 20234

December 1981

Final Report

Issued January 1983

\section{Prepared for}

Department of Energy

Under Contract No. EA-77-A-01-6010

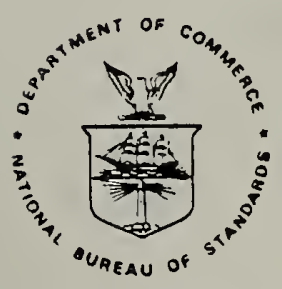

U.S. DEPARTMENT OF COMMERCE, Malcolm Baldrige, Secretary NATIONAL BUREAU OF STANDARDS, Emest Ambler, Director 
Executive Summary

1. Purpose of Survey 3

a. Survey Approach 4

b. Types of Pulp and Paper Mills 7

2. Pulp and Paper Making Measurement 9

Technology Requirements

a. Feedstock 9

b. Pulping Processes 12

1. Mechanical Pulping 12

2. Chemical Pulping 13

3. The Sulfite Process 14

4. The Kraft or Sulfate Process 14

c. Pulp Washing and Bleaching 18

d. Process Stean 24

3. Chemical Recovery - Kraft Process 24
a. Recovery Boiler
27
b. Smelt Bed 31
c. Lime Kiln 31

4. DOE-Sponsored Measurement Technology

Research and Development 33

5. Conclusion and Observations 34

Appendix - Survey Questionnaire 38 



\section{Execut ive Summary}

Seven pulp and paper mills, two research institutions, an instrumentation manufacturer, and one corporate Instrumentation and Control group were visited to obtain the points of view of the plant operating personnel and others concerned about the need for new sensors and measurement instruments. Most of the information developed is in agreement with the generally perceived needs that have been reported in the literature during the past several years. Acknowledging that six mills is a very limited sample of the large pulp and paper industry, several of the points of view were significant either because the mills were unanimous in voicing a need, or conversely, the mills placed the needs for some sensors as low priority items. For example, sensors to measure the moisture in the wood chips did not appear to be an important need, particularly in the mills located in climates where freezing is an unusual condition.

On the other hand, all of the mills expressed a need for a reliable, on-line sensor capable of measuring the consistency of multi-phase flows. Associated with the need for consistency sensors was a desire for a sensor to measure the "freeness" of the furnish, i.e., the drainage characteristic of the water comprising the majority of the pulp slurry to drain from the sheet formed by the cellulose fibers when the slurry is incident on a screen. Such is the initial procedure in forming the paper sheet. In this case, some agreement needs to be established on the cháracteristics of "freeness." 
The pulping process is the least controlled of the papermaking processes. Several measurement needs were identified in this area. On-line measurement of the degree of completion of the digestion process would provide the required information to control the digestion process. Also various measurement technologies are needed to improve process control of the chemical recovery cycle. The prominent energy-intensive processes of this cycle are the recovery boiler and the lime kiln. The recovery boiler is of most interest since its chemical reduction capacity limits pulp production rates in many mills. Some parameters of interest here are: (1) fuel value of black liquor; (2) solids concentration; (3) combustion zone temperature; and (4) smelt bed parameter, i.e., degree of chemical reduction.

Several additional sensor needs were also discussed, and these sensors are identified in this report.

It is apparent that the continuing increase in fuel costs is of concern to the pulp and paper industry. New sensors that would result in the decreased use of energy would be welcome. However, it is improbable that any sensor would be accepted unless it has been proven to be reliable, to require infrequent calibration, to be relatively maintenance free, and to not require a very high level of training to operate. 


\section{PURPOSE OF SURVEY}

A survey of selected paper mills was conducted in order to identify the needs for improved sensors and measurement techniques. By visiting selected paper mills and reviewing applicable documents, the survey gathered experiences and recommendations from paper plant operating personnel, and paper plant instrumentation engineers.

This report of the survey includes an assessment of the process control equipment used in the pulp and paper industry and discusses the future needs for sensors as perceived by the industry. The survey revealed that the priorities of needs for sensors as viewed by the personnel responsible for paper production may be significantly different from the priorities as seen by the instrumentation specialist.

The following pulp and paper mills were visited to obtain the information discussed in the field survey.

$\begin{array}{ll}\begin{array}{l}\text { Mead } \\ \text { Westvaco }\end{array} & \text { Chilicothe, Ohio } \\ \text { St. Regis } & \text { Pensacola, Florida } \\ \text { International } & \text { Mobile, Alabama } \\ \text { Scott } & \text { Mobile, Alabama } \\ \text { Southwest Forest Industries } & \text { Panama City, Florida } \\ \text { North Pacific Paper } & \text { Longview, Washington } \\ \text { its were made to the Accuray Corporation, Columbus, Ohio; a } & \\ & \end{array}$




\section{a. Survey Approach}

The pulp and paper industry can be characterized as a "mature" industry involving processes that require large amounts of energy. Although approximately one-half of the energy used is derived from forest and pulp waste products, the remaining energy requirements are supplied by oil, gas, and/or coal. The majority of the pulp and paper mills now in operation were built during the years when the costs of fossil fuel energy were very low, and consequently the design of energy efficient systems was not given the attention it would be in today's era of high energy cost. All of the mills surveyed have improved or expanded their plant facilities since construction, one has been in operation only a short time, but the primary emphasis has been on improving the paper making process. Improving energy efficiencies is a part of many recent plant improvement programs, but these improvements still appear to be of secondary importance. There are strong indications, however, that if fossil fuel prices continue to increase faster than the inflation rate, most mills must improve their energy efficiencies if they are to remain competitive.

The interviews followed the general line of questions that are listed in the last section of this report. These interviews with the technical staff of several operating paper mills indicate an awareness of the need for better instruments in order to improve energy efficiencies, but the interviews also revealed a practical concern regarding the cost/benefits of improved instrumentation and computer control. Much of this concern is the result of unsat isfactory experiences with instruments that were unreliable, or required constant maintenance, or required highly trained (and highly-paid) technicians to operate. 
Since the purpose of this field survey was to obtain the views of the pulp and paper industry personnel regarding the needs for new or improved sensors, the industry's concern with the practical usefulness of instrumentation in a relatively unsophisticated production environment was found to be an important factor in the selection of any sensor research and development program.

In order to relate the specific comments of mill personnel to specific mill operations, this report will include brief generic descriptions of typical mill processes, followed by the recommendations and comments received during the survey. The basic unit operations and intermediate products in the making of paper using the Kraft or sulfate process are diagrammed in Fig. 1. 


\section{KRAFT PAPER MAKING PROCESS}

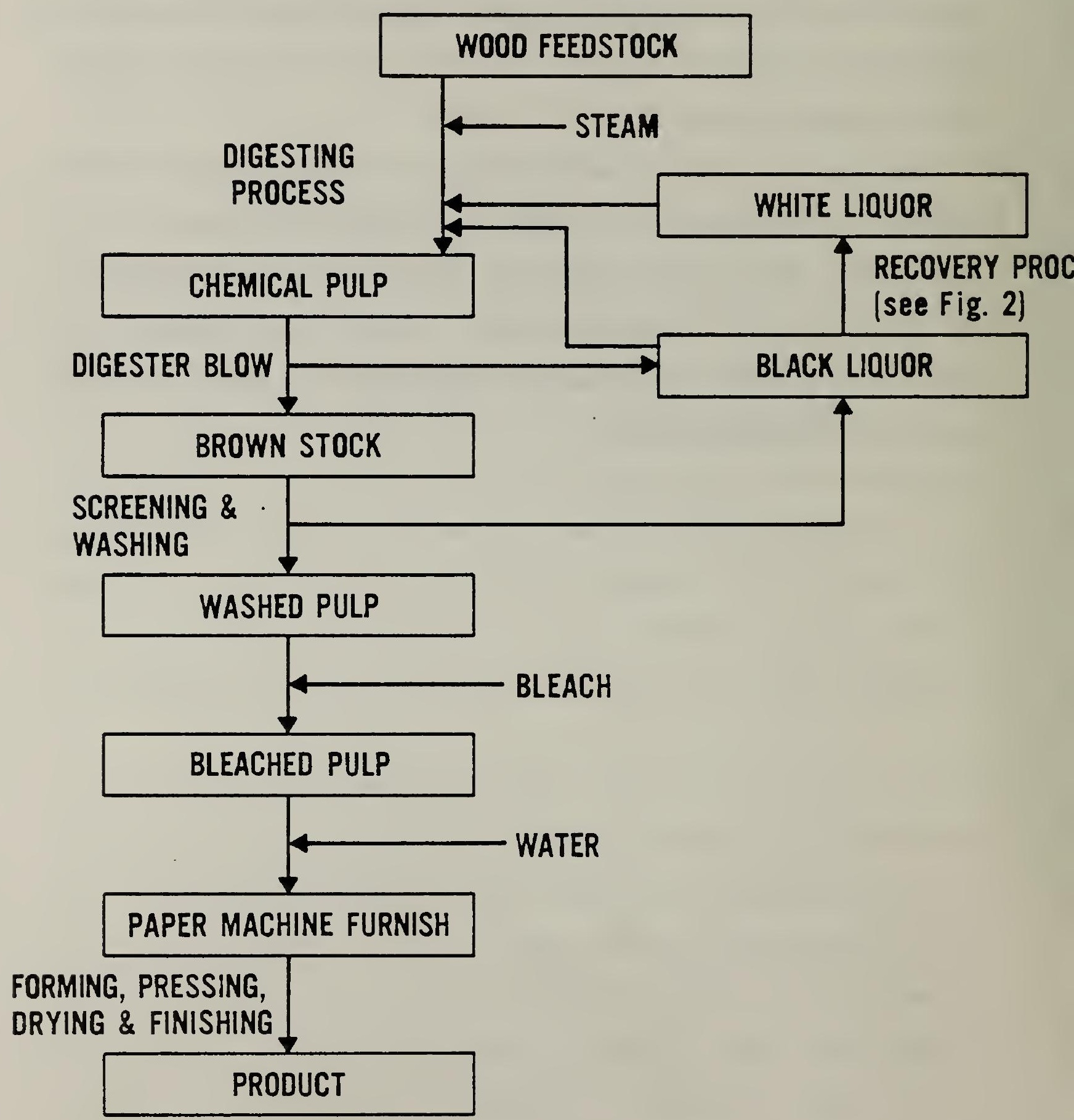




\section{b. Types of Pulp and Paper Mills}

Over 350 companies manufacture paper and paper products and over 700 mills are located in the U.S. to produce pulp and paper. Producers vary in size from very large installations that produce wood products, as well as pulp and paper, down to relatively small specialty paper mills. Although some mills produce quality paper from rags and other fibrous materials, most of the raw material for paper is obtained from trees and recycled waste paper.

Mills are generally classified as either integrated mills, or non-integrated mills. The distinguishing difference is whether a mill produces its own pulp to be made into paper, in which case it is an integrated mill, or whether it purchases its pulp and/or waste paper, which identifies it as a non-integrated mill.

It has been estimated that $60-70 \%$ of the production capacity is in integrated mills. The average capacity of an integrated mill is 300,000 tons per year. However, the large new mills have production capacities of 500,000 to $1,000,000$ tons per year. These mills produce their own electric power unless they are located in an area where electric power such as hydro-electric power is relatively cheap. According to the American Paper Institute, all paper mills in the U.S. with annual capacities greater than 360,000 tons are fully integrated.

The non-integrated mills that manufacture paper from purchased pulp and waste paper have papermaking capacities ranging from 3,000 to 30,000 tons per year. Almost all of the non-integrated mills purchase their electric power as well as the feedstock for-the paper. Recognizing that although some new sensors may be needed by non-integrated mills, it is apparent that most of the needs for new or better sensors and instruments 
will come from integrated mills, especially sensors needed in the digesting and chemical recovery processes. Consequently, this survey emphasized visiting and interviewing personnel from fully integrated mills. 


\section{PULP AND PAPER MARING MEASUREMENT TECHNOLOGY REQUIREMENTS}

\section{a. Feedstock}

With the exception of specialty paper mills that use rags and other non-wood fibrous materials as feedstock, the feedstock for integrated mills is almost exclusively wood in the form of sawdust, chips, or mill residues. By far the largest percentage of feedstock is in the form of wood chips, and an increasing amount of the chips is produced in the forest by machines that chip the whole tree instead of just the tree trunk. Unless the wood is obtained from a plantation in which all of the trees are of the same species, the wood chips from a hardwood forest will be from a number of tree species. Variability in hardwoods will result in differences in paper properties. Most mills do not pulp mixtures of hardwood and softwood chips because they respond differently to liquor penetration and pulping kinetics.

In looking to future requirements, the supply of good long fiber softwoods might not be adequate to meet the increasing demand for pulp. If this type of supply/demand condition should develop, it would result in an increase in demand for short-fiber hardwoods and probably lower quality feedstocks in general with possible changes in requirements for facilities and instrumentation. An increase in usage of lower quality wood would also require more intensive bleaching to produce white papers.

These expected changes in the feedstock could initiate or accentuate the demands for new sensors, particularly on-line measurement of the Kappa number, and the wood-to-alkali measurements. Kappa number is a measure of the concentration of lignin compounds in a sample of pulp or process liquor, usually spent digestion liquor. This process variable results from an off-line titration involving permanganate solutions. 
The sources of wood fibers are: (1) roundwood or wood chips obtained from forests owned by the pulp and paper mills, or (2) log or wood chips purchased from private suppliers within the general area surrounding the mill. Some mills reported problems in digesting purchased chips. In particular wood chips from some undesirable species such as swamp cypress can cause problems, and chips containing waste material from plywood plants are particularly troublesome because of the glue used in the plywood. Mill operators would welcome a sensor that could detect these contaminants prior to storage and pulping.

Wood chips, either purchased or chipped by the mill, are normally stored in a stockpile of sufficient size to insure that continuous pulp production would not be affected by any small-duration interruption in the wood supply. During its storage, the moisture content of chip can change, depending principally on weather conditions.

In the colder climates, rain and melting snow can be troublesome if this moisture is frozen around the chips. The moisture of chips in the stockpile will vary with respect to its location in the pile.

Knowledge of the chip moisture content is needed in order to regulate the cooking schedule to meet the target Kappa number. Many mills sample chips, usually twice during a work shift for moisture determination in the laboratory. The moisture content information is then transmitted to the personnel responsible for digester operations, and adjustments are made to the cooking schedule to compensate for any changes in the moisture content. Obviously, infrequent samples that are analyzed off-line can be effectively used only if the moisture content is subject to relatively slow changes, which is usually the case in warmer climates. A11 of 
the paper mills visited use off-line sampling, and most do not consider on-line moisture content to be a high priority need. However, one mill was testing an on-line sensor at the time of the plant visit. The results of these tests were reported to be favorable at the 12 th Annual Instrumentation and Control for the Pulp and Paper Industry held at Miami University of Ohio, May 1981. The indications are that the mills in the colder climates might use on-line moisture sensors if they are low cost and reliable. In order to avoid the problem of frozen chips, some mills in the colder climates stockpile the chips in silos or bunkers. In this case, one mill expressed a need for a reliable instrument to indicate the level of chips in the bunkers. 


\section{b. Pulping Process}

The three principal commercial processes used to convert wood into pulp are: (1) mechanical pulping, (2) sulfite chemical processes, and (3) sulfate (or kraft) chemical processes ( $\sim 70 \%$ of U.S. pulp production).

1. Mechanical Pulping

This process produces pulp through the direct mechanical abrasion of wood either in chip form or in the form of round wood. Four types of processes are used:

1. Stone grinding of wood,

2. Refiner mechanical pulping (RMP),

3. Thermomechanical pulping (TMP),

4. Chemithermomechanical pulping (CTMP).

These processes have approximately twice the yield $(\sim 90-95 \%)$ of the kraft process since the lignin binding the cellulose fibers together is not removed. These processes are electrical energy intensive. Approximately $1500 \mathrm{kwh}$ is needed to produce a ton of pulp using the ground wood process with RMP and TMP consuming 2000 to $2500 \mathrm{kwh} / \mathrm{ton}$. Plants employing these processes tend to be located in regions of cheap electric power. The U.S. Pacific Northwest and Canada contain most plants using this process. The ground wood and RMP processes employ little pretreating of the wood while TMP and CTMP use presteaming or presteaming combined with mild chemical treatment before the wood goes to the refiner. One or two refiner stages may be used to produce the pulp depending upon its use. A primary control parameter for this process is freeness which is a measure of the ability of a pulp to release the water used to transport it once it is placed on the fourdrinier screen of a paper machine as well as a predictor of some paper strength properties. 
Freeness and consistency are the primary parameters used for control of the thermomechanical pulping ( TMP) process. This process consures a large amount of electrical power to produce pulp. In the newest plant visited, each refiner plate was driven by a 5,000-horsepower electric motor. Approximately 250,000 horsepower is used to process pulp for two large paper machines producing newsprint. Freeness values were obtained from grab samples and laboratory derived results were entered into the automatic control system by the operator of the process. Approximately two hours elapsed between samples. In this particular mill the level of automatic control capability is extremely high. Every attempt has been made to use on-line measurements. In the case of freeness these on-line sensors required a high level of maintenance and were felt to be unreliable by mill personnel. Mill operation relied upon off-line laboratory measurements for process control information. Reliable freeness measurements on-line would allow active control of the TMP process resulting in a significant savings of electrical power through more rapid and effective feedback control of the TMP process.

\section{Chemical Pulping}

The purpose of a chemical pulping process is to separate cellulose fibers from the major non-cellulose constituents of wood; the major constituents are cellulose, hemicellulose, and lignin. Cellulose is a colorless carybohydrate. The whiteness of the fiber, which is mostly cellulose, is caused by dispersion of light in the fiber body. Cellulose is fairly resistant to the action of the chemicals normally used in the papermaking process. Lignin, the name for a complex polymeric organic compound, is the second main constituent and is the substance that binds the fibers together. Of particular importance to the pulping process is 
the fact that hardwood lignins are quite different from softwood lignins. A considerable body of work has been published on the characteristics of these lignins. A definitive reference work on the subject has been published by Sarkanen and Ludwig [1].

\section{Sulfite Process}

The sulfite pulping process uses an acid sulfite solution to digest the wood chips. Although once a relatively popular pulping process, the number of mills using the sulfite process has remained approximately constant since 1940. The difficulty of pollution abatement has played a strong role in decreasing the attractiveness of these process in recent years. The growth of the U.S. pulp and paper industry during this century has been based largely on the Kraft pulping process. The advantages of the sulfite process on a commercial basis are:

1. High yield,

2. Low cost of process chemicals (sulfurous acid and calcium bisulfite) relative to the Kraft process,

3. High brightness of unbleached pulps,

4. Ease of bleaching without use of chlorine dioxide.

However, two major disadvantages of the sulfite process relative to the Kraft process are:

1. A limit of range of woods are suitable as feedstock,

2. Significantly reduced strength of the pulp,

3. Difficult pollution abatement.

\section{Kraft or Sulfate Process}

The kraft or sulfate pulping process is the predominant alkaline process in use today. The kraft process uses sodium hydroxide and sodium sulfide as the pulping chemicals. The advantages of the process are: 
1. The pulp has high strength,

2. Any wood specie can be used,

3. Substantial bark can be tolerated in the chips,

4. The digestion process is short,

5. Problems with pitch are less prevalent,

6. Chemical recovery is a well understood process,

7. Commercially useful by-products (turpentine and tall oil) are available from some softwood species.

The remaining portion of this report will deal largely with the Kraft process, since most of the paper mills surveyed for this report use it.

In the Kraft process, alkaline chemicals with a pH of greater than 12 are used to chemically remove most of the lignin and hemicellulose in order to free the desired cellulose fibers. The digestion process is operated at elevated temperatures and pressures in large vertical cylindrical digesters. The digester is charged with wood chips and "white" cooking liquor and black liquor. It is then closed and the wood chips are cooked or digested from two to three hours at temperatures of 340 to $350^{\circ} \mathrm{F}$, and at pressures of about 100 to $150 \mathrm{psig}$. The active chemicals in the cooking 1 iquor are sodium sulfide and sodium hydroxide. The strength of the white 1 iquor is expressed in terms of active or effective alkali, which is defined as the combination of concentrations of sodium hydroxide and sodium sulfide expressed in terms of the equivalent sodium oxide. All of the mills surveyed using the kraft process used off-line titration to measure the effective alkali in the liquor. Some types of on-line sensing for active or effective alkali are in commercial use. These use titration or conductivity sensing. 
All of the kraft mills surveyed used banks of batch digesters. Up to 18 batch digesters are in use in some mills. Since continuous digesters are relatively recent systems, batch digesters were the only kinds of digesters in use when these mills were built. Within recent years at least two of the mills visited have added continuous digesters, and another mill is planning to add a continuous digester. Some mills have automated chip charging systems, but most batch digesters are still charged manually. The batch digesting cooking cycle normally consists of three steps:

1. Pressure raising and penetration of liquor,

2. Cooking period under full pressure at the cooking temperature,

3. Pressure reducing step. The pulp is usually blown from the digester under pressure.

Batch digesters are either heated by direct steaming of the wood-liquor mixture or by indirect steaming of the cooking liquor as it is circulated through side-arm heat exchangers connected to the digester vessel itself. The process control variables involved in the digestion process are:

1. Composition of cooking liquor,

2. Concentration of cooking Iiquor,

3. Chemical to wood ratio,

4. Temperature and time.

The most important factors are the temperature and time of the digestion process. In addition the liquor volume must be controlled to assure an optimum consistency of the pulp when it is blown from the bottom of the digester. The flash steam released in the blowing process is partially recovered in the form of hot water. This hot water is then used 
for washing and bleaching the pulp. In continuous digesters, the three steps of heating, cooking, and blowing take place in different zones of the digester. The flash steam is captured and used to heat the chips being fed into the digester.

The cooking time for batch digesters is determined by the Kappa number of the previously cooked pulp, i.e., the measure of the lignin compound concentration of the pulp. A sample of the pulp is taken during the pulp-blowing step, and is analyzed to determine its kappa number. Determination of the kappa number of the sample is accomplished with an off-line wet-chemistry test. Depending upon the type of pulp to be produced, the kappa number is used to determine the alkali-to-wood ratio, and the temperature and cooking time to be used for the next batch. Only one of the mills visited had batch digesters equipped with devices that enable the extraction of pulp samples during digestion. These samples are also analyzed off-line and could be used to modify the cooking process to meet the pulp quality desired. Normally, the test results of these samples were used to control the processing of the next batch. None of the mills visited use any on-line sensors to determine the Kappa number during a cook, nor were the mill personnel familiar with any sensor that could make on-line Kappa number or equivalent measurements.

In fact, if an on-line Kappa number sensor were developed, there may be a reluctance to use such a sensor in some mills. Old-time pulp mill operators take pride in their abilities to grab hand samples of the pulp during the digester blow, and to estimate its Kappa number by its color, texture, and feel. On the other hand, mill and corporate personnel responsible for instrumentation and control agreed that a low cost, reliable on-line Kappa number sensor must be developed in order to eventually achieve real-time computer control of this process. 
Another method for controlling the Kappa number of the pulp is to blend the pulp after digestion. By mixing a number of batches of pulp in the pulp storage tanks, the kappa number for the pulp that will go to the paper machine can be controlled within a desired range suitable for the type of paper to be manufactured.

One of the documents reviewed during this survey listed the $\mathrm{Nu}$ and permittivity measurement tests as other pulp quality measurement tests. None of the mills visited make these tests, nor did there appear to be any interest in them.

c. Pulp Washing and Bleaching

All chemical pulps must have additional treatment after the pulp is discharged from the digester. The first step in the treatment is to wash the pulp with hot water in order to remove a major portion of the lignin still adhering to the cellulose fibers and residual alkali chemicals. The washing process is usually performed in a series of steps. Before the washing process, uncooked wood pieces (knots and shives) are removed, and bundles of fibers are broken into separate fibers.

From an energy conservation point of view, control of the pulp washing (sometimes called brown stock washing) is important because the efficiencies with which the chemicals are recovered and the hot water reused will determine the amount of process heat that will be required. Effective evaporator efficiency will minimize the amount of dilution which the black liquor will experience before passing to the evaporators. Since evaporation requires process heat, a high concentration of solids in the black liquor will decrease the amount of steam required to increase the solids concentration in black liquor to be safely fired in the recovery boiler (60-65\% solids). An alternate process using freeze crystallization 
of the water in black-liquor-dissolved organic and inorganic salts is currently the subject of research efforts. It is anticipated that use of this process for black liquor dewatering will provide a significant energy reduction.

Following the washing process, the pulp is bleached to varying degrees of brightness determined by the type of paper to be produced. Brightness measurements are based upon reflectance intensities in several regions of the visible spectrum. Typically, these colors (red, green, blue) are used although others may be used for particular types of paper or pulp. For example, kraft pulp which will be made into liner board is not bleached, while pulps to be used for high quality writing papers are bleached to a high degree of brightness. Bleaching is a process of solubilization and removal of colored material from the pulp after digestion. Kraft pulps are dark in color as they leave the digester, due to residual lignin adhering to the cellulose fibers. Since lignin is easily chlorinated, it $c$ an be efficiently removed if the first step in bleaching is chlorination followed by alkaline extraction. Caustic is used to extract the chlorolignins formed in the first stages -- for the most part, and chlorine, hypochlorites, and chlorine dioxide are used to remove lignin in the subsequent stages. The use of chlorine dioxide will produce high-strength, high-white pulps. However, chlorine dioxide is one of the most expensive chemicals used in the paper making process and itself is produced in an energy intensive process.

Bleaching is usually either a three stage or a five stage process. The plants surveyed used the five stage bleaching process. The bleaching process involves several washings, chlorination, alkaline extraction, hypochlorite, and/or chlorine dioxide treatment. Each stage is usually 
subjected to an appropriate form of measurement to achieve process control. Chlorine is the principal bleaching chemical, and between 125 and 150 lbs of chlorine are required for each ton of white paper. The chlorine bleaching process is usually controlled by measuring the brightness of the treated pulp using optical reflectance methods. This particular measurement technique was used by all of the mills surveyed. The degree of alkaline extraction is determined off-line in the laboratory. Measurement of the concentration of hypochlorite is also performed off-line usually by using the oxidation-reduction-potential (ORP) technique. On-line measurement is used but not in the mills visited. All of the mills surveyed stated that the existing techniques of measuring and controlling the bleaching process were effective and did not give the mills any significant problems. Therefore, the mills did not consider the development of on-line bleach process sensors to be urgently needed.

After the pulp has been bleached, it is filtered, thickened and then stored in a thick stock tank before beginning preparation for paper making. This final processing procedure or approach flow to the paper machine is highly dependent upon the type of paper to be made. A wide variety of additives may be used to obtain the desired paper characteristics.

A major energy consumer in this final processing stage is the refining or beating process. The refining process is electrical energy intensive. Refiners generally consist of a stator and rotor or two rotors, either conical or disc shaped, driven by large electric motors ( 500-1000 hp). Control of the procedure is accomplished through variation of the residence time, consistency, and gap between the stator and rotor. Paper pulp having a consistency of approximately 4 to $6 \%$ is mechanically 
abraded changing the physical characteristics of the cellulose fiber to produce desirable properties of the paper sheet formed from them. (Consistency is defined as the mass fraction of cellulose in the pulp slurry, i.e., it is the solid phase fraction of this particular solid-liquid system.) Sheet strength and sheet formation are strongly influenced by refining. The process variable used extensively to measure the degree of refining is freeness. Freeness is a measure of the drainage of water from the fiber mass formed by the pulp as it drains over a screen. The standard test most often used in the U.S. is the Canadian Standard Freeness test which is an off-line test. On-line sensors which measure drainage characteristics were not given a high degree of confidence by the operating personnel surveyed. High levels of maintenance were claimed necessary to maintain operation and there was a general lack of confidence in the measured values derived from these devices. Since this parameter is of such importance to the paper making process, a high level of interest was expressed in the development of reliable and effective freeness measurement techniques with reliability and low maintenance being primary considerations.

Having been refined, the pulp slurry has entered the approach flow system to the paper machine. This stage of the process will produce the final pulp slurry or furnish which contains all necessary components to the paper sheet having specific ranges of properties. The furnish may be a complex blend of selected pulps, fillers, dyes and/or whiteners such as titanium dioxide for producing high quality writing or printing grades of paper or may contain unbleached stock for producing linerboard, whose primary specifications relate to strength characteristics. These processes occur before the stock is diluted to a consistency of 0.1 to $1 \%$ 
and may use unit processes of a specialized nature to obtain the desized paper properties. These procedures were not surveyed and tend to be either proprietary or nonenergy-use specific and were, therefore, not considered in this survey. Dilution of the stock from the 3 to $4 \%$ consistency level to the proper consistency is done using the white water taken from the paper machine. This is the water used to carry the furnish through the head box to the Fourdrinier screen. This water falls through the screen or is sucked off through the couch roll and recirculated to the blending point. Once again, consistency is the controlling parameter for the dilution. Although this is not an energy-intensive procedure it is very important to paper making since sheet properties, e.g., basis weight (mass per unit area of paper sheet) and variation in it, are sensitive to the final consistency in the head box and at the slice (the orifice through which the pulp slurry passes from the headbox onto the fourdrinier screen). Feed forward control of the linear speed of the paper rachine is common and based in part upon the consistency measurement of the furnish. At this point, accuracy of the consistency measurement is more important than previously since sheet properties depend directly upon absolute consistency measurements rather than relative variations.

All of the mills surveyed state that they would place a high priority on developing a reliable and accurate on-line instrument for measuring consistency. Several indicated that not only is it important to measure the consistency at the headbox and in the blending process, but such an instrument would also be useful in other parts of the process particularly in the digesting, bleaching, cleaning, and refining operations where consistencies are in the 3 to 12 percent range. Great care is exercised in measuring the volumes or weights of water and materials but, in spite 
of this, variations in consistency will occur, requiring frequent checking. Taking a sample of stock from any point in the system is not a reliable technique. Experience has demonstrated that such samples can vary by 10 percent in the consistency value. Although numerous types of consistency sensors are available and in use, many of the mills surveyed were not satisfied with their performance. In particular, the sensors based on hydrodynamic drag of the flowing stock required frequent maintenance and were generally claimed to be unsatisfactory but better than no sensor at all.

In a recent survey by the American Paper Institute of technical support personnel in pulp $(\sim 30 \%$ of the respondents $)$ and paper $(\sim 70 \%$ of the respondents) mills, devices based on hydrodynamic drag were predominant $(\sim 95 \%)$. The primary deficiencies of these devices were their sensitivity to flow conditions, vibration induced by high flow velocities, and plugging. The majority of the respondents felt that further instrument development work was needed. Poor reliability and excessive maintenance were often cited as problems with this type of device. These devices appear to be used for relative consistency measurement. Absolute consistency measurements are not considered possible presently but would be a desirable feature.

Freeness plays an important role in the papermaking process. Freeness will affect the first step in the drying process and the initial drainage of water from the screen on the fourdrinier screen followed by additional water removal by a suction coach roll at the end of the screen. As the sheet enters the machine's rolls, the first rolls remove more water by pressing the sheet against a felt roll. The remaining water is removed by evaporation which occurs on steam-heated rolls of the paper sheet 
passes through the drying sections of the paper machine. The dryer section of a paper machine is enclosed by hoods to reduce the amount of process steam required, some of the mills surveyed expressed a need for reliable humidity sensors in the hood area. Humidity sensing was being used in at least two mills, but these sensors required frequent maintenance. The humidity sensors provide information for control of the recirculation of air in the dryer hoods, thereby reducing a tendency to overdry the paper sheet.

\section{e. Process Steam}

Process steam is consumed primarily in the digestion process, in drying the paper sheet once it has been formed through various evaporation processes. It is the most energy-intensive fluid found in a paper mill. In most cases. the metering of steam to the various unit processes was not done. There was a general feeling among those interviewed that a reliable and accurate steam flow measurement would induce more efficient use of steam throughout a mill. Accurate measurement would also provide a method for energy usage in the various unit processes of papermaking and could provide an incentive to improve efficient utilization of it.

One mill visited did not produce process steam since the pulping process was thermomechanical. Steam was purchased from a nearby producer. Both producer and user emphasized the need to measure the energy content of the steam. The user stressed the need for improved steam flow measurements having increased dynamic range in the flowrate (current devices have a $3: 1$ range) and the capability to measure the energy content of the stear. Improved control and energy utilization characteristics of the papermaking as a whole could result from such measurements of this primary form of energy. 


\section{CHEMICAL RECOVERY PROCESS}

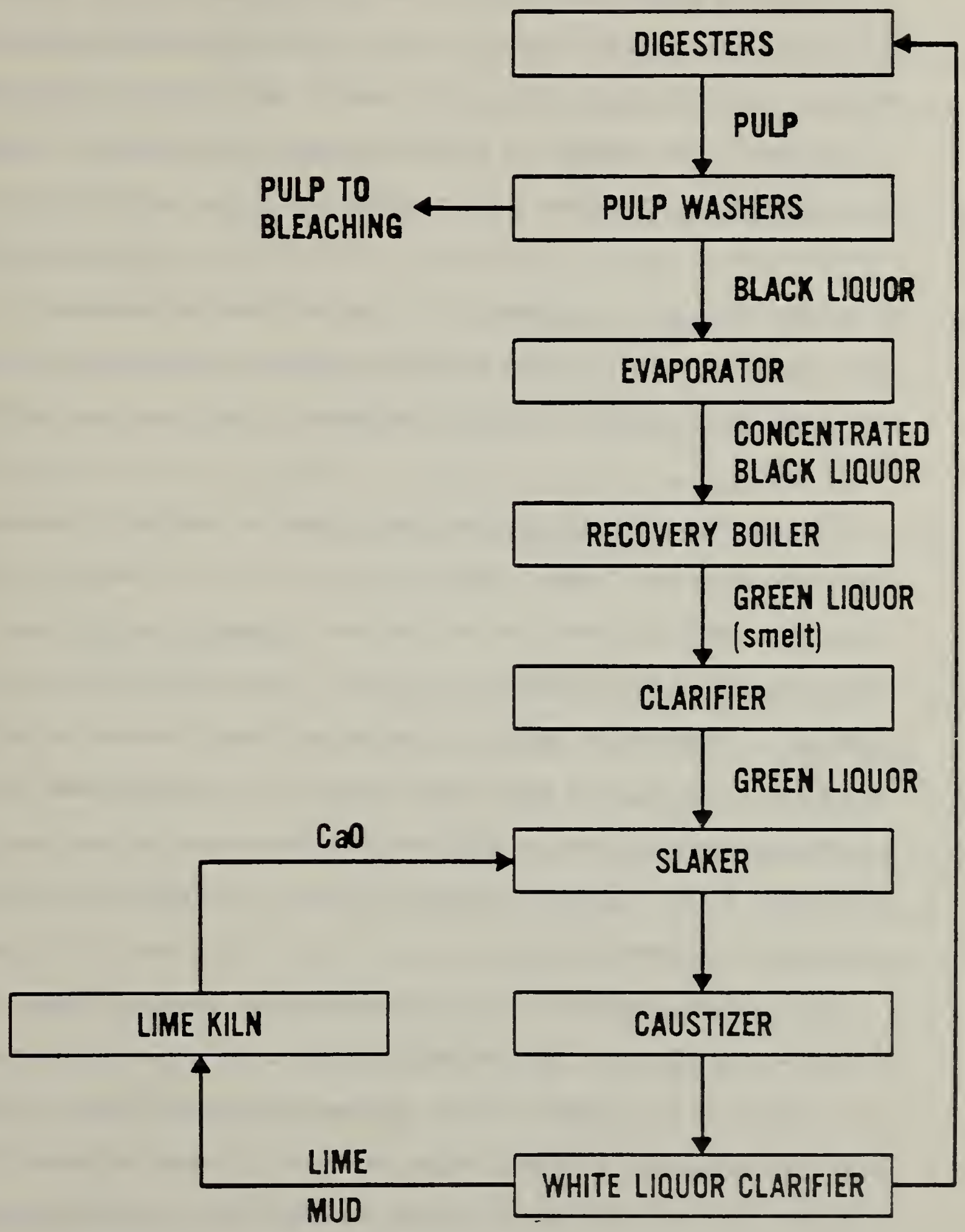


3. Chemical Recovery

The kraft pulping process that is described in the first sections of this report is a sulfate chemical process. One of the advantages of this process is its ability to recover and recycle most of the chemicals used. In addition to the recovery of valuable chemicals, the chemical recovery system generates enough heat in the combustion of the waste lignin and carbohydrates to provide a substantial portion of the process heat needed to operate the mill. A schematic of a typical chemical recovery loop is shown in Fig. 2. The two most energy-intensive processes are the recovery boiler and the lime kiln. Energy is produced in the boiler and consumed in the kiln.

The chemical recovery process starts with the washing of the pulp to remove the dissolved lignin, hemicellulose, and process chemicals. The wash water remaining after the pulp has been cleaned is called black liquor because of the characteristic black color caused by the dissolved organics. A substantial portion of the black liquor is recycled and added to the white 1 iquor to be used in the digestion of another batch of chips. The remaining black liquor is oxidized to reduce odors and then sent to evaporators where the concentration of solids is increased by multi-effect evaporation to remove the water.

Multi-effect evaporators use water evaporated from one stage to act as the heating fluid for the succeeding stage. Typical evaporators will have as many as six stages, and can increase the concentration of solids from about $15 \%$ to $50 \%$. Recent safety standards require the black liquor to have $60-65 \%$ solids before it can be burned in the recovery boiler. Since corrosion and high viscosity preclude the use of multi-effect evaporators above concentrations of $50 \%$, the final concentration step is 
achieved by heating the black liquor in the hot flue gas stream from the boiler. Optical refractometers were used in all cases to assure that concentration of solids will be a minimum of $65 \%$ before injection into the recovery furnace. None of the mills surveyed indicated any problems with using refractometers, although some of the technical personnel at the mills felt that a more direct measurement of solids concentration would be desirable.

Measurement of the dew point in the contact evaporator was cited as a useful measurement. Condensation of sulfuric acid on the metal surfaces of the evaporator causes excessive corrosion ultimately leading to replacement of the evaporator. A sensor to do this measurement was considered desirable although direct energy conservation would not result from its use.

\section{a. Recovery Boiler}

The recovery furnace is a major component in a kraft paper mill. Not only is it necessary in the chemical recovery step, but it usually also supplies enough heat energy as process steam to operate the digesters. The operating principle of a recovery furnace is to burn the combustible lignin in the black liquor in a staged combustion process. Two types of furnace designs are used. The first [2], sprays the black liquor from two nozzles located in opposite walls of the furnace. The nozzles are on oscillating mounts; the flow through them and their shape are selected to spray the liquor through the combustion zone of the furnace so that it strikes the opposite wall where it adheres, dries, and may begin combustion. After drying on the wall, the dry residue slumps off the wall and falls onto the bottom of the furnace into the smelt bed where it completes combustion of the hydrocarbons and the chemical reduction of the liquor. The smelt flows 
out the bottom of the furnace through spouts into the dissolving tank. Steam jets break up these smelt streams before they hit the surface of the liquid in the tank to avoid explosion of the hot smelt as it comes into contact with water. This type of furnace uses three locations for the introduction of combustion air. Primary air is introduced near the top of the smelt bed, secondary air enters immediately above the liquor injection ports, and tertiary air is admitted 10 to 15 feet above the secondary air ports.

The second type of recovery furnace is similar in general characteristics but differs in the method of introduction of the black liquor and combustion air. In this case the black liquor is sprayed through a system of nozzles located on all four sides of the furnace at the same level. Up to four individual nozzles may be located on each side of the furnace. The spray of black liquor from a nozzle is a dispersed spray of droplets whose trajectories carry them into the combustion zone of the furnace where they fall to the surface of the smelt bed. During transit the droplets dry and burn. Again, primary combustion air is introduced near the top of the smelt bed. Secondary combustion air is introduced approximately 15 to 20 feet above the black liquor injection point. In both types of Eurnace designs sufficient heat is released by the burning lignin to maintain the reduction reaction in the smelt bed producing the desired sodium sulfide.

Although easy to describe in generalities, the operation of a recovery furnace is relatively complicated. While the lignins and other organic matter in the black liquor are the primary fuels, supplementary gas or oil may also be burned simultaneously to provide combustion stability or to make up for low black liquor availability should the digestion process not be providing a sufficient supply. Enhanced combustion stability is 
considered possible if the fuel or calorific value of black liquor were measured to adjust firing levels to compensate for the fuel's variable energy content. No on-line sensor is available to measure this variable, therefore furnace control and operation must allow a substantial safety margin. Unfortunately, catastrophic furnace explosions have occurred due to either large breaks in the water walls of the furnace or to firing black liquor containing too much water. This latter cause is one of dispute within the community. In any case, the need for on-line fuel content measurement as a control variable for the recovery boiler was voiced by operating and technical personnel and would provide increased automatic control capability. In this case the time necessary for an acceptable sensor to provide fuel content information would be on the order of every few minutes ( 5 to 10 ). This was claimed to be entirely acceptable.

The other major variable of the recovery boiler combustion process, air was either not measured or done poorly in the mill personnel's opinions. At least two of the mills surveyed were strong in their criticism of existing techniques, and expressed a conviction that more accurate air mass flow instruments could be beneficial in improving the operating efficiency of the furnace. Generally, few if any direct measurements are available from the combustion region itself.

Additional parameters which were cited as being needed but not presently available, or available but at an unacceptable level of operation are listed below:

1. Oxygen and Co concentration in the furnace cavity. Presently sensors are available for both variables to be measured in the stack emissions. These measurements have been shown to improve control of the boiler. 
2. Instrumentation to monitor particulate emissions from the recovery furnace cavity. These are primarily sodium sulfate and sodium carbonate. These inorganic salts exit the furnace $\left(1700^{\circ} \mathrm{F}\right)$ and enter the boiler tube banks $\left(1200^{\circ} \mathrm{F}\right)$ where fouling and corrosive effects may be severe. The level of "stickiness" of these particulates is dependent upon temperature. Corrosion of the boiler tubes results from excessive temperature in the furnace which is frequently overfired to increase chemical production. Surface temperature measurements on the boiler tubes would be used to control the temperature of the furnace to keep particulate temperatures below critical values.

3. Various black liquor parameters need to be measured:

a. Flowrate of liquor as it is fed to the boiler's spray nozzles,

b. Droplet size distribution as it is sprayed from the nozzles droplet sizes should influence the drying and combustion characteristics of the liquor,

c. More accurate solid concentration,

d. Viscosity - influence on droplet size is the object here, e. Surface tension, a key parameter of the spray-droplet formation process.

4. Detection of leaks in the boiler tubes at the pinhole size.

5. Vertical temperature profile of the furnace from the smelt bed to the boiler tubes.

No on-line sensors are presently being used to measure the combustion properties of the recovery boiler. This dearth of available sensors must be 
remedied to effectively control the boiler's operation efficiently.

\section{b. Smelt Bed of the Recovery Boiler}

The primary function of the recovery boiler is the reduction of sodium sulfate to sodium sulfide. These reduction reactions occur in the smelt bed which lies on the hearth of the furnace. The boiler is operated such that the smelt bed is maintained between 1700 and $2200^{\circ} \mathrm{F}$. The smelt is drawn off from the furnace hearth while still molten and dissolved in weak liquor and water. The smelt bed parameters which were most frequent ly given as critical measurements needed for control purposes are listed below:

1. Surface temperature profile,

2. Smelt bed height and/or profile (topography),

3. Sme1t bed inventory or density,

4. Temperature and flowrate of the liquid smelt as it comes from the bed,

5. Sulfate to sulfide conversion rate, bed reaction rates generally,

6. Sodium carbonate concentration in the smelt and the green liquor produced from it.

The harshness of this environment is such that few if any bed parameters are made even on an intermittent basis. Periodic visual inspection is the usual practice. Visual inspection allows the bed height to be maintained at 2 to 3 feet.

\section{c. Lime Kiln}

Although the recovery furnace is a ma-jor component in the recovery and recycling of chemicals, additional chemical processes and equipment are needed to return the chemicals to the state from which they $c$ an be used again in the pulping process. As shown in 
Fig. 2, the smelt is drawn from the furnace hearth while it is still liquid, and is then dissolved in weak liquor and water. The resulting solution is transported to a clarifying tank in which the solids settle out, after which it is called green liquor, a color caused by dissolved iron sulfide.

The green liquor contains sodium sulfide and sodium carbonate. The sodium carbonate is converted into caustic soda by treatment with slaked lime ( $\mathrm{CaO})$ and calcium carbonate is precipitated as lime mud. The causticized liquor, now called "white" 1 iquor is clarified and ready for recycling in the pulping process. Fresh white liquor is diluted with black liquor up to $60 \%$ by volume to maintain the water balance favoring energy conservation in the recovery process. The lime mud (calcium carbonate) is passed through a lime kiln to be reformed into $\mathrm{CaO}$. The lime mud is injected into the high end (gas exhaust end) of a rotary kiln and progresses through the slowly turning kiln until the calcined product, $(\mathrm{CaO})$ is discharged at the lower end. Oil or natural gas is used for heating the kiln. The burners are located at the lower end of the kiln and the hot gases pass to the high end, or counterflow to the mud flow.

Although the kiln is a major consumer of fuel, most of the mills surveyed have not installed sophisticated control systems. The mills visited were using manual controls. The temperature at the burner end is measured with an optical pyrometer, and the temperature composition of the exhaust gases is measured with standard sensors. Most mills have yet to install air preheaters to recover some of the sensible heat from the discharged $\mathrm{CaO}$. No active attempts to control airflow into the kiln were observed. The parameters for which measurements were desired are listed here: 
1. Flame temperature profiles and emissivity,

2. Lime temperature profile along the kiln length,

3. Mass flow of lime mud into the upper end of the kiln,

4. Quality of the discharged lime in terms of actual CaO available to convert $\mathrm{Na}_{2} \mathrm{CO}_{3}$ to white liquor.

Due to concentration and reaction equilibrium the reaction proceeds usually at less than $90 \%$ efficiency. Hence, unreacted 1 ime and sodium carbonate circulate through the kiln as a "dead load." Energy is wasted in the calcining process since these materials must be dewatered and converted again.

The lime kiln is a large user of energy. Several corporate research personnel have stated that research directed toward the use of alternate energy sensors in this process could be useful to decrease the industry's dependence on natural gas. Combustion-related research was also suggested for the effective burning of less desirable fuels such as bark, waste paper, and wood unsuitable for paper making or other uses.

4. DOE-Sponsored Measurement Technology Research and Development

As part of the contract under which this report has been written, the Department of Energy is supporting a research and development effort directed toward producing measurement technology which will provide the basis for the private sector to develop new on-line sensor technologies which will be available in a paper mill environment. The objective is to enhance the efficient utilization of energy through the increased use of automatic control systems. At this time the barrier to broadened use of these systems, which are well developed, is process variable measurement information, e.g., consistency, freeness or black liquor properties. 
As part of this effort, an industry working group has been assembled to provide expertise. As part of the initial phase of this activity, this working group compiled a list of sensor needs for the paper industry which would improve energy utilization and the process generally. The following 1 ists the process parameters chosen by the committee as those of highest interest and potential impact to the industry in this area.

1. Kappa number ( 1 ignin concentration in the pulp mass),

2. Pulp quality (freeness),

3. Steam flow,

4. Active alkali,

5. Black liquor combustion,

6. Smelt bed parameters,

7. Black liquor characteristics,

8. Lime kiln temperature profile,

9. Solids concentration of black liquor,

10. Consistency,

11. Chip moisture,

12. Bulk chip density.

This list is not given in priority order. In generating the list the working group used energy conservation as a general guideline along with the conclusion of previous analyses which indicated that the pulping and recovery areas were those in which the use of new sensor technology would significantly enhance the use of automatic control system in these areas.

\section{Conclusion and Observations}

The need for new and better process instrumentation and controls for pulp and paper mills has been the subject of several technical conferences during the 
late $70^{\prime}$ s and has also been studied by consultants under contract to the Department of Energy. A review of applicable proceedings and reports indicate that while there has been a considerable amount of discussion about the need for better sensors, there is a diversity of opinions concerning the feasibility of using new sophisticated instruments in existing facilities. The survey of the mills visited for this report indicate that the operators of the paper mills are well informed on instrumentation and control systems, and would favorably consider using new sensors and techniques. As one of the technical staff at a paper mill observed, "... any on-line sensor technology would be of use". However, reliability in the plant environment is a key consideration to the acceptance and use of new measurement technologies.

The need for new measurement rechnologies which will improve energy utilization in the paper industry is most pronounced at the pulping end of the process. The kraft and thermomechanical pulping processes are energy intensive and presently cannot be effectively controlled because no sensor technology exists to do the job. Specific needs have been listed in this report for these processes. Research efforts directed toward developing the basic knowledge needed to support the development of on-line sensor technology is sparse. Although many of the paper companies maintain research and development activities, these efforts tend to be short range and do not emphasize the type of research, i.e. instrument ation technology, needed which will ultimately provide the basis for development of on-line sensors for the pulping process. The same situation exists with the instrumentation and control comanies with process control hardware. Although control algorithm system production capability is well developed in these companies, they are not supporting long- 
term research which may provide the basis for an on-line measurement technique unless fruitition of the effort is expected in a reasonably short period of time.

The American Paper Institute supports research activities at The Institute of Paper Chemistry and universities. These tend to be of various types but few in the area of new process measurement technology. At this time the U.S. Department of Energy has supported and is supporting research related to energy conervation technologies and some of these are long-term research oriented.

The following areas are ones which will be useful throughout the pulping and paper making processes in addition to being required for achieving efficient control of the pulping process.

a. Thermomechanical Pulping (TMP)

1. Freeness - The prevailing opinion in the community is that a correlation(s) must be found between fiber properties which can be sensed remotely, and drainage of water from the paper sheet on the fourdrinier screen. Some work has been done here but either it is not available to U.S. manufacturers or it has not been successful. A broader definition of the properties of interest is usually designated as pulp quality, i.e. those fiber or pulp characteristics which combine to form paper of a desired type. This parameter not only applies to TMP-produced pulp but also to pulp produced by any process as that pulp is refined for final properties in the approach flow to the paper machine.

2. Consistency - Currently available sensors are not doing the job in the opinion of most of the people and companies surveyed. New and different methods are needed to produce a sensor insensitive to 
other parameters; e.g., flow velocity or other fluid dynamic properties. Again this variable is a key one in the refining operation of the approach flow to the paper machine.

\section{b. Kraft Pulping Process}

The sensor needs here lie in two distinct areas. The first which relates to the digestion process is the need for measurement of the residual lignin adhering to the cellulose fibers during or immediately after completion of digestion. Kappa number is the most frequently mentioned parameter here. Effective or active alkali concentration measurement during digestion would be effective here. The primary barrier here is the harshness of the environment, i.e. high temperature, pressure, and a highly corrosive environment.

The second area is that of chemical recovery and power generation. The primary needs here relate to combustion science; temperature measurements in the combustion zone for recovery and utility boilers and for the lime kiln; fuel property measurements; and measurements related to the process product, e.g., smelt bed parameter measurements in the recovery boiler and lime kiln temperature profile. 


\section{APPENDIX I}

The variety of opinions regarding the use of existing instruments and the need for new sensors can be illustrated by reporting the response given to a list of questions that were verbally answered by the personnel in the mills that were surveyed. The questions and responses are presented in the following summary. The numbers following each response indicates the number of mills giving this answer.

\section{Pulp and Paper Industry Field Survey}

1. Feedstock

1.1 What is the raw material used in this facility?

Response: Wood chips (7), ground wood (1), short wood (1), plywood waste (1)

1.2 Is the moisture content measured? If so, how and when? Response: Occasional check, samples analyzed in lab (5), None (2)

2. Chemical Pulp and Bleaching

2.1 Does this facility use batch digesters, continuous digesters or both?

Response: Batch only (3), batch and continuous (3)

2.2 If this facility uses batch digesters, how is the flash steam that is released during blowing used?

Response: Accumulated as hot water and used to wash pulp (5), preheat boiler feed water (1)

2.3 What characteristics of the pulp, in addition to its kappa number, are used to determine its readiness to leave the digester? 
Response: None (4), alkalinity test of white liquor (1), visual examination of "pull" sample (1)

2.4 Is the active alkali measured? When and how?

Response: Manual titration (6)

2.5 How is the alkali-to-wood ratio determined?

Response: Off-line coulometric titration (4), by formula (2)

2.6 Are any of the following measurements made in this mill?
a. Nu number
Response: No (6)
b. Permittivity
Response: No (6)
c. Optical reflectance
Response: Brightness of samples (4)
Prior to chlorination

d. Gamma ray densitometer Response: Nood density (2)

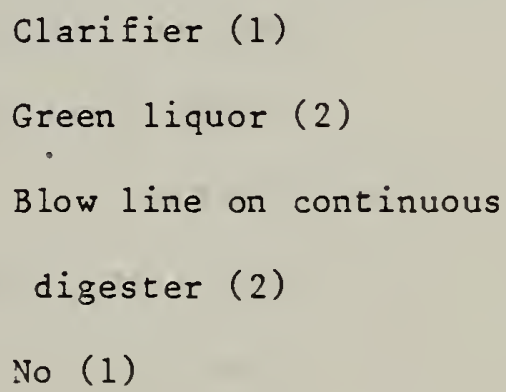

f. Refractometry Response: Black liquor (6)

2.7 Is chlorination measured? If so, how?

Response: Oxidation reduction potential (ORP) ( 3 ), optical measurement (3), extracted kappa number (1)

3. Chemical Recovery System

3.1 Which of the following measurements are made? How? White liquor causticity Response: Laboratory titration (6) 
Furnace temperature

Flue gas temperature

Stack emissions

Black liquor dry solids

Black Iiquor viscosity

Black Iiquor surface tension

Smelt bed weight

Response: None (6)

Sodium bed light intensity Response: None (6)
None (3)

Response: Thermocouple (4)

None (2)

Response: 0 meters (4)

Unknown (2)

Response: Refractometers (6)

Off-line analys is ( 1 )

Response: None (4)

Off- I ine (2)

Response: None (6)

4. Paper Making

4. 1 How is consistency measured?

Response: Vane type instruments (3), strain gauges (2), shear pipe (2)

5. Sensor Needs

5.1 What new kinds of sensors would be useful if they were available?

1. Better consistency measurement instruments

2. Humidity sensor in paper machine drying section

3. Portable and accurate non-intrusive flow meters for liquids

4. Portable chip moisture sensor

5. Accurate and reliable air mass flow measurement instrument recovery boiler

6. Sensors to warn of imminent sodium explosion 
7. On-line density sensors for green liquid

8. BTU sensor for black liquor

9. On-line viscosity meter for black liquor

10. System to optimize use of electric power

11. On-line active alkali sensor

12. Sensor to measure dew point at bottom of wet precipitator In summary, this survey of six large pulp and paper mills belonging to six different corporations reinforces previous studies that indicate a need for better sensors in the paper industry. Some plants indicated that their needs were urgent, while at the other end of the scale, one plant production manager felt that his plant was "over-controlled" with the exception of a few instruments. An almost universal opinion expressed dissatisfaction with existing commercially available instruments. 


\section{References}

[1] Sarkenen, K. V. and Ludwig, C. H., Lignins-Occurrence, Formation, Structure and Reactions, Wiley-Interscience, John Wiley \& Sons, New York, N.Y., ISBN 0-471-75422-6.

\section{General References}

1. Pulp and Paper - Chemistry and Chemical Technology, edited by J. P. Casey, Vol. 1-3, John Wiley and Son, New York, N.Y., ISBN 0-471-03175-5.

2. Clark, J. d'A., "Pulp Technology Treatment for Paper", p. 504, Miller Freeman, San Francisco, 1978.

3. Steam/Its Generation and Use, Chapter 26, Babcock and Wilcox, Inc., 1978, New York.

4. S. S. Fam, "Impact on Energy Conservation of Automatic Control Systems Utilization in the U.S. Pulp and Paper Industry", Thermo-electron Report 非TE4265-20-80 (1979).

5. "Concise Notes for Students of Papermaking and Boardmaking," The Paper Maker, July 1979 through January 1972. 

NBS-114A (REV. 2.8C)

U.S. DEPT. OF COMM.

BIBLIOGRAPHIC DATA

SHEET (See instruction s)

1. PUBLICATION OR REPORT NO.

NBSIR $83-2640$
2. Performing Organ. Report Nod 3. Publication Date

FEBRUARY 1983

4. TITLE AND SUBTITLE

Sensors for Efficient Energy Utilization in the Paper Industry

5. AUTHOR(S)

J. R. Whetstone, E. G. Johnsen

6. PERFORMING ORGANIZATION (If joint or other than NBS, see instructions)

NATIONAL BUREAU OF STANDARDS

DEPARTMENT OF COMMERCE

WASHINGTON, D.C. 20234

7. Contract/Grant No.

EA-77-A-0.1-6010

8. Type of Report \& Period Covered Final

9. SPONSORING ORGANIZATION NAME AND COMPLETE ADDRESS (Street. City, Stote, ZIP)

Department of Energy

Washington, DC 20585

10. SUPPLEMENTARY NOTES

$\square$ Document describes a computer program; SF-185. FIPS Software Summary, is attached.

11. ABSTRACT (A 200-word or less factual summary of most significant information. If document includes a significant bibliography or literature survey, mention it here)

A survey of the on-line process measurement needs of the paper industry has been completed. The survey focused on pulp and paper mills with one corporate Instrumentation and control group and one instrumentation and control systems manufacturer included. The results of the survey strongly indicate the need for new measurement technology at the pulping end of the process. Important unit processes identified are: (1) chemical recovery (recovery boiler and lime $\mathrm{kiln}$ combustion measurements); (2) digestion (lignin concentration measurement in the pulp or spent liquor); and (3) thenmechanical pulping (consistency measurement). All of the processes are energy intensive and cannot be controlled either partially or completely due to the lack of measurement of specific process parameter.

12. KEY WORDS (Six to twelve entries; alphabetical order; capitalize only proper names; and separate key words by semicolons) Instrumentation; measurement technology; paper manufacturing; pulping; recovery boiler.

13. AVAILABILITY

$x$ Unlimited

For Official Distribution. Do Not Release to NTIS

$\square$ Order From Superintendent of Documents, U.S. Government Printing Office, Washington, D.C. 20402.

14. NO. OF

PRINTED PAGES

X Order From National Technical Information Service (NTIS), Springfield, VA. 22161

45

15. Price

$\$ 8.50$ 


